To cite this article: Dickinson, J.E., Hibbert, J.F. \& Filimonau, V. (2016). Mobile technology and the tourist experience: (Dis)connection at the campsite. Tourism Management, DOI: 10.1016/j.tourman.2016.06.005.

\title{
Mobile technology and the tourist experience: (Dis)connection at the campsite
}

\begin{abstract}
Mobile technology is playing an increasing role in the tourist experience and a growing body of tourism research has focused on this area. There is often an implicit assumption that tourists embrace mobile connectivity and relatively little research has explored the tourist experience of disconnection, whether purposeful or imposed by technological limitations. This study explores the desire for digital (dis)connection during camping tourism. Data compiled using interviews and a survey revealed that the tourist is not 'always connected' and up to $50 \%$ have some desire to disconnect. There is ambiguity about mobile technology use in tourism with dilemmas regarding the value of connectivity versus the desire to 'get away from it all'. The analysis found digital engagement had a small effect on desire for disconnection however, patterns were not marked. The findings have implications for mobile technology solutions in tourism.
\end{abstract}

Keywords: mobile technology; smartphone; digital connection; tourist experience

\section{Introduction}

Mobile technology has considerable utility in the tourism domain since tourists are on the move in unfamiliar environments and seek information to resolve practical travel problems and to enrich the tourist experience (Gretzel, 2010). Mobile devices have become central to the tourist experience of some users (Neuhofer, Buhalis \& Ladkin, 2014; Wang, Xiang \& Fesenmaier, 2016), opened up new marketing and communication opportunities (see for example, de Oliveira Nunes \& Mayer, 2014; Kang \& Gretzel, 2012) and created new challenges for a service based industry where word of mouth recommendations have a powerful influence (Buhalis \& Law, 2008). The opportunity to exploit mobile technology has been grasped by tourism providers, computer scientists seeking new domains for their expertise and tourists alike. In response, a growing body of research has sought to understand how mobile technology can best be harnessed by the industry (Buhalis \& Law 2008). Much of this research has focused on enhancing technological solutions for the tourism domain (see for example, Neuhofer et al., 2014) and tends to assume mobile technology use will continue to grow, be widely embraced and add to the tourist experience. A second strand of research has taken a more critical stance to understand how mobile technology reconfigures tourism (see for example, Germann Molz \& Paris, 2013; Gretzel, 2010; Hannam, Butler \& Paris, 2014) and even de-values the experience (Neuhofer, 2016). While tourists' use of mobile technology has grown rapidly, there is less research taking a critical view of the value of this technology and questioning the often implicit assumption that mobile technology is a desirable contribution to the tourist experience, though there is recognition of the potential for exclusion due to digital divide (Gretzel, 2010; Hannam et al., 2014). Lalicic and Wesemayer (2016, p.10) suggest tourism research in this field is in an "emerging state".

Evidence is emerging of a tourist backlash to the pervasiveness of technology in everyday life. New terms are emerging such as 'digital detox' (Lay, 2014) and 'digital switch-off' (Gretzel, 2014). 'Digital addiction' is widely discussed in the human computer interaction literature (see for example, Lalicic \& Weismayer, 2016; Samaha \& Hawi, 2016; Turel, 
Serenko \& Bontis, 2011) and digital disconnection in tourism has been associated with positive wellbeing (Smith \& Puczkó, 2015). Therefore, while much of the research in tourism assumes mobile technology will become indispensable to the tourist and add to their experience, relatively little research has critically explored tourists' desire to disconnect or how tourists negotiate constant connectivity (Paris, Berger, Rubin \& Casson, 2015). Those seeking to disconnect are likely to not only see little value in attempts by industry to engage them with technology, but may also resent the need to use mobile technology where this has become essential in some contexts.

This paper emerges from a project that was primarily involved in developing and testing a mobile technology solution in the tourism domain. Early in the project it became apparent there were various barriers to mobile technology adoption and engagement which were explored throughout the project. The focus of this paper is on digital (dis)connection, the desire to remain connected or to disconnect within a tourism setting. The aim is to analyse the extent of digital (dis)connection, its relationship with mobile engagement and the impact on use of a purpose built tourism app. The study context was UK camping tourism, but has implications for mobile technology solutions in the wider tourism field and particularly in rural tourism. The paper makes a theoretical and practical contribution in three respects. First, there is currently comparatively little research addressing a desire to disconnect in tourism. This study therefore makes a contribution in measuring the current extent of the phenomena and analysing demographic patterns. Second, use of mobile technology is related to digital engagement, including social motivations such as social media use in other domains (Kim, Kim \& Wachter, 2013), however, studies have yet to analyse whether these patterns translate to the tourism setting where tourists may be seeking to go off grid. Third, the development of mobile technology solutions in tourism assumes that tourists will have and be willing to use an appropriate mobile device. This paper therefore explores the impact of digital (dis)connection on desire to use a purpose built tourism app which will enhance knowledge of the viability of technological solutions in the tourism domain.

\section{Digital (dis)connection in tourism}

The interest in this paper is focused on mobile devices, especially mobile phones which are small, easily carried and practical to utilise in most tourism contexts. Mobile phones have increased in sophistication with smartphone ownership now outstripping other forms of mobile devices (ownership of smartphones stood at 76\% in the UK as of September 2015) and heading towards market saturation (Mintel, 2015a). Smartphone developers have increasingly embedded a range of functionalities into devices that are of value to the tourist. Use patterns vary but have been categorised into: logistical (for example, seeking travel updates during tourism); relational (for example, use of social media); informational (for example, exploring local tourism opportunities); and mobile entertainment (for example, gaming or watching videos) (Campbell \& Kwak, 2011). A similar categorisation has been applied to later work in the tourism context: facilitation, communication, information search and entertainment (Wang, Xiang \& Fesenmaier, 2014) and Lalicic and Weismayer (2016) extend this by discussing emotional support. These capabilities are enhanced in mobile devices by a raft of sensors, such as GPS and accelerometers, which enhance context awareness (Dickinson, Ghali, Cherrett, Speed, Davies \& Norgate, 2014; Gretzel, 2010). Smartphones potentially add value across all phases of the tourist experience: anticipation; travel to destination; destination based activity; return travel; and recollection (based on Clawson \& Knetsch, 1966), though tablets and personal computers may play a greater role in the first and last phases. Smartphones have also increased tourists' ability to engage in the pre and post consumption phases during the core consumption experience, removing the need for advanced planning and facilitating changes of plans (Dickinson, Filimonau, Cherrett, Davies, Norgate, Speed \& Winstanley, 2013; Fotis, Buhalis \& Rossides, 2011; Wang et al., 2014). However, Gretzel (2010) argues the tourist experience is altered by 
mobile devices which can cause disengagement leading to disembodied experiences, a loss of sense of place and lack of interaction with those physically present.

The value of smartphones in tourism was initially curtailed by the additional costs of use outside of the tourist's country of origin, however, legislation has reduced the costs of calls, texts and data roaming, and will reduce this further in 2017 (European Commission, 2015). Also, more widely available free Wi-Fi has almost eliminated this obstacle in most contexts. Signal quality and availability is also an issue in some tourism destinations, particularly rural areas, however, the shift to a 4G network has improved the coverage and speed of connection although there are still 'dead zones' where users are unable to connect (Pearce \& Gretzel, 2012) even in developed countries.

The capacity of mobile technology to transcend space/time so users can be in two spaces or times is widely reported in other fields (Humphreys, 2010; Sheller, 2004; Wilken, 2010; Wittel, 2001) and mobile devices have reshaped a variety of social practices (Llamas \& Belk 2013; Wajcman, 2008) such as shopping, banking and working. Some people, but far from all, can work at home, while travelling and during tourism (Dickinson \& Peeters, 2012). This blurring of work and leisure space and time has been referred to as 'fragmented time' (Klein, 2004) and 'digital elasticity' (Pearce, 2011). MacKay and Vogt (2012) have used spillover theory to explore how technology use at home can transfer to tourism. It is arguably no longer normal to be disconnected and Wang et al. (2014) found that tourists were influenced by subjective norms, specifically peer mobile use patterns, and that routines of smartphone use from everyday life pervaded the tourist experience. However, there are questions about whether this is desirable (Brooks \& Longstreet, 2015; Llamas \& Belk, 2013; Neuhofer, 2016), for example, Paris et al. (2015) found remaining connected to work while a tourist can be a blessing, but also cause anxiety and sociologists have explored in general whether technology weakens, reinforces or supplements co-present sociability (Fortunati, Taipale \& de Luca, 2013).

The use of mobile technology in tourism has led to a growing body of research which can largely be categorised into three streams (Wang et al., 2014): human computer interaction studies focused on optimising design of systems (for example, tourism apps and guides); adoption of mobile information services mainly using the Technology Acceptance Model and its derivatives; and the impact of technology on the tourist experience. Studies largely assume connection is a positive thing and an opportunity to be harnessed by the industry that will enhance tourist experiences and business opportunities. The concept of 'technology dead zones' emphasises negative connotations of places where connection is unfeasible, though this can lead to positive experiences (Pearce \& Gretzel, 2012) and the selective nonuse of smartphones needs to be explored further (see for example, Wang et al., 2014). Also work on disconnection has been largely related to where backpackers find themselves unable to connect, though within this there is some discussion of purposefully choosing to disconnect, for instance when users temporarily want to hide their whereabouts (Germann Molz \& Paris, 2013). There is also evidence from travel news media of a growing number of destinations and hospitality service providers offering tourism products where you can disconnect (see for example, Lay, 2014), although in her work on dead zones Gretzel (2014) questions whether this will have much appeal. Outside the tourism field studies have shown extensive digital engagement can have some consequences for health (Harwood, Dooley, Scott \& Joiner, 2014) and intrusion of technology has other negative effects (Llamas \& Belk, 2013).

An extensive body of research suggests tourism contributes to well-being and quality of life (Uysal, Sirgy, Woo \& Kim, 2016), however, the understanding of this relationship is less clear (Moscado, 2009). Tourism is based on the premise of a separation from home and work life that contributes to well-being (Krippendorf, 1987). Turner (1977) has theorised this as a liminoid experience that is likened to a contemporary rite of passage. The separation 
requires both physical travel and also a state of mind which depends on how much cultural baggage comes with the tourist (Jafari, 1987). This is captured by the escape motive in tourism literature (Dann, 1981; Hall, 2003; Krippendorf, 1987) however, mobile connectivity alters the idea of escape (Neuhofer, 2016). Though tourists who travel to other places clearly physically escape their home and work surroundings, they can now easily remain connected and interact with the home environment. While this digital elasticity (Pearce, 2011) is generally seen as desirable, some studies are finding evidence of tourists seeking to disconnect at least some of the time (Paris et al., 2015). The growing body of research in this area therefore raises questions about the reality of the 'escape' motive in contemporary society and how it is now realised. Llamas and Belk (2013) highlight that research on digital consumption in most disciplines has largely focused on digital connection, therefore, given that explorations of tourism are shaped by the hegemonic social representations academics hold (Moscado, 2009), there is a need for research to explore assumptions about the (dis)connected tourist.

This paper extends the research on disconnection. It examines this in the mundane context of domestic camping tourism that has not been specifically marketed as a 'digital detox' experience. Camping has remained very popular in Europe with many tourists involved (17\% of the total overnight stays in the EU (EuroStat, 2012)) and campsites account for a large proportion of beds in the study destination area (approximately 50\%, Purbeck Heritage Committee, 2002). Despite this camping tourism remains under researched (Mikkelsen \& Cohen, 2015). It can be the main holiday, a second or third holiday, or a weekend away.

Camping tourists are a diverse group that reflect different levels of involvement in nature from purely recreational to more spiritual (Hassell, Moore \& Macbeth, 2015; Vespestad \& Lindberg, 2011). The setting represents a place where many people choose "to engage with a simpler, "past time", that is devoid of the technological devices that proliferate in their dayto-day lives" (Dickinson et al., 2013, p.16). It is a shared experience (Dickinson, Filimonau, Hibbert, Cherrett, Davies, Norgate, Speed \& Winstanley, 2016) that has been broadly analysed through three lenses: freedom (Hardy, Gretzel \& Hanson, 2013; Mikkelsen \& Cohen 2015), social bonding and engagement with nature (Hassell et al., 2015; Garst, Williams \& Roggenbuck, 2009). The main motivation is re-creation, aligned with notions of escape, but research also points to the value of camping in individuals' identity projects (Garst et al., 2009; Hassell et al., 2015; Vespestad \& Lindberg, 2011). Disconnection while camping offers opportunities for social bonding and contact with nature as technology can distract from desired relationships (Hassell et al., 2015) and awareness of the natural environment (Garst et al., 2009). Successful family functioning (see, Hibbert, Dickinson \& Curtin, 2013) is particularly important and technology can be perceived to detract from this in the home environment (Garst et al., 2009). On the other hand, connectivity can assist with tourists' identity work through the ability to share good stories (Patterson, Watson, Leopold, Williams \& Roggenbuck, 1998) while on the move (Munar \& Jacobsen, 2014). In 2009, Garst et al. (2009, p. 95) identified mobile devices as part of an emerging comfort and convenience of camping which alongside other camping technologies make experiences "more pleasant and less laborious", an example of technology spillover from everyday life (MacKay \& Vogt, 2012). Garst et al. (2009, p. 103) see technology as a buffer in camping as people seek nature but also convenience, pointing out the "irony that people seek to escape from modern life but never fully divest themselves of the modern comforts that they say they are trying to elude". Recent market research in the UK (Mintel, 2016) indicates some desire to stay at campsites which encourage digital disconnection and, in the USA, Camp Grounded (http://campgrounded.org/) offers digital detox. Given the focus on camping tourism, the findings of this study are not transferable to all tourism contexts, particularly urban, where there is evidence mobile technology may be perceived and used differently (Eden, Gretzel \& Mistilis, 2013). They are likely to resonate in rural tourism settings most notably adventure sports, ecotourism and agritourism. 


\section{Methodology}

A sequential mixed methodology strategy was deployed. The first stage involved exploratory in-depth interviews which raised questions about digital connection in a tourism context. The project then sought to explore these issues in a quantitative survey to understand patterns within a wider population. The focus of this paper is on the latter. While there are epistemological concerns about mixed methodology approaches (Bryman, 2001), in the sequential approach adopted, the qualitative analysis informed the design of the quantitative study, a distinct and separate phase. This is compatible with the post-positivist paradigm adopted (Guba and Lincoln 1998) where the researchers took the epistemological perspective that they are likely to have some influence on the findings, however, objectivity was sought as far as possible. Methodologically, the study took place in a natural setting, UK rural camping tourism.

The choice of rural camping tourism was central to the wider aim of the project which focused on developing and testing a mobile technology solution to aid sustainable tourism in this context (Dickinson, Cherrett, Hibbert, Winstanley, Shingleton, Davies, Norgate \& Speed, 2015). The interviews took place from October 2011 to September 2012 at a campsite in Purbeck, Dorset, UK. The campsite was chosen since it reflects features of other medium sized campsites in the region and tourists were a range of family, couple and friendship groups engaged in typical tourist activities including visiting beaches, local attractions and engaging in outdoor activities. The campsite management had no active policy on digital disconnection. Wi-Fi was not available, but mobile devices could be charged for free and the campsite has a web and social media presence. In total, 48 interviews were conducted each lasting around 40 minutes. The interviews focused on different aspects of the project but all included open ended questions on the use of mobile technology as a tourist. A theoretical sampling strategy was employed (Giles, 2002) with a heterogeneous sample of participants recruited to capture a range of camping tourists (group characteristics (family, couples, friendship groups), age ranges, repeat and first time visitors, and gender). A thematic analysis strategy focused on how participants talked about mobile technology use in the campsite tourism context, what and who influenced mobile use, and their approaches to use.

At the end of the qualitative phase a questionnaire was developed to explore a range of issues within the project with a wider sample. Digital disconnection emerged as a concern in the qualitative work and this was therefore incorporated into the questionnaire design as a Likert-type scale question (strongly agree to strongly disagree). The questionnaire was piloted autumn 2012 and spring 2013 and the main study was conducted in summer 2013 across three campsites in the Purbeck area. A sampling frame for caravan and camping sites was derived from tourist information material. Three campsites were purposefully chosen to reflect varied location contexts in Purbeck, different campsite characteristics, campsite size and reasonable accessibility to the research team. The accommodation structures of the three sites required different on-site delivery strategies. Two sites were dominated by tents and most tourists could be approached outside their tents (sampling during wet weather was avoided) and the whole site was traversed in the course of a visit. The third site was dominated by mobile caravans, including recreational vehicles, where tourists were not always outside. Here the researcher stood in a prominent position near the campsite facilities to hand out questionnaires to every adult as they approached.

The pilot study was conducted over 8 days and achieved 110 responses with a response rate of $37 \%$. The pilot was designed to test and refine a raft of statements that measured a number of latent variables including digital disconnection. Following the pilot a number of items were dropped from the measurement scales following exploratory factor analysis leaving the most robust items to measure the concept. The main survey was conducted over 16 days with a response rate $47 \%$. This was higher than the pilot since the questionnaire 
was shorter and conducted during warmer conditions when respondents were more willing to take part. Questionnaires were given out predominantly in the morning and late afternoon when tourists could be found at the campsites. Comparative analysis of the pilot and main study data revealed no differences for corresponding statements therefore data was combined for the main analysis. Following screening for missing answers the final sample was 339. The sample reflects the family orientation of UK camping (57\% were aged $35-54$ and $55 \%$ were accompanied by children) which has also become more affluent and educated in recent years (66\% had post-18 qualifications and $33 \%$ had household income over $£ 50,000)$. Women were slightly over represented $(57 \%)$ and $95 \%$ were British. The analysis used descriptive statistics and then derived a factor score for digital (dis)connection to explore relationships with personal variables and mobile engagement.

\section{Findings}

\subsection{Dimensions of the digital (dis)connection experience in tourism}

Two themes emerged from the qualitative analysis related to the digital connection experience in camping tourism. First participants raised connectivity problems due to hardware issues related to poor mobile and/or data signals, lack of easily accessible charging facilities at campsites and concerns about damage to phones while camping. Those with smartphones were particularly mindful of the need to charge phones, especially where they used location based data using GPS which tends to deplete the battery rapidly. In some respects participants viewed camping as a 'technological dead zone' (Pearce \& Gretzel, 2012) where they would have very limited or no internet connection. In this respect disconnection was forced on some participants (Figure 1), however, during the course of the project (2011-2013) these connectivity issues improved. 4G improved rural data access, campsites improved charging facilities and most cars could charge phones without the ignition on. At the campsite concerned, phones were originally left with the reception staff to charge, however, this proved time consuming for staff. The solution was a raft of electric sockets made available to campers, and though this provided no device security, campers seemed content to leave high-end smartphones charging unattended. Therefore technologically enforced disconnection dissipated and did not continue as a focus of the study, however, it remains an issue in some rural tourism contexts.

Second, some participants expressed a desire to switch off mobiles to manage digital intrusion, however, views on this varied. Participants described a number of mobile technology conflicts with the camping tourism experience which included: intrusion from work; desire to escape day-to-day activities; a desire to be immersed in the natural environment often aligned with a bucolic image of rurality; conflict within the camping group due to the impact of mobiles on family and social interaction; and a desire for children to disengage from technology. Much of this reflects a view that virtual environments detract from physical proximate environments (see for example, Neuhofer, 2016) and relationships (see for example, Turel et al., 2011), though this is a complex interaction (Hannam et al., 2014). These mobile use preferences can be grouped into personal preferences and interpersonal influences (Figure 1).

With respect to personal preferences, several participants felt mobile technology presented a dilemma in the campsite context as day-to-day life spills over (MacKay \& Vogt, 2012; Wang et al., 2016), for example, Karen reflects on work intrusions describing how:

"It's a double edge sword isn't it? It's meant that so many things that were very difficult to research and do are at your fingertips, but it also means that everybody wants to be, has an expectation of being in touch with you all of the time, and 
expects you to be able to answer your emails every minute and respond to texts all the time."

In a similar vein, Alice opted to turn off her mobile as she "came camping to get away from it all", but recognised it could be of value "if you needed something you'd turn it on". Here Alice adjusts her mobile use to the tourism setting in order to manage connectivity to immerse herself in the tourist experience (see Lalicic and Weismayer, 2016). This reflects the strategy adopted by several other participants. Michael specifically relates this to the natural context:

"In London, you know, yeah, it is... in the city environment... it seems a very natural thing... whereas out, you know, in the countryside it does not... it is not relevant and it is actually quite nice not having that. Personally speaking... it is nice to switch off."

Others expressed more irritability about mobiles. For example, Mark refers to "this thing [mobile phone] that stops you experiencing the now" illustrating how mobiles can interfere in the tourist experience (Lalicic \& Weismayer, 2016). Similarly Ruth describes her enjoyment of being in the countryside and a sense of relief that she is not so contactable: "I actually enjoy not being so dependent... waiting for it to ring or trying to sort things out, it is just nice to think, this is my time-out". Here technology can form a barrier to experiencing the natural environment (Garst et al., 2009; Neuhofer, 2016) and these issues reflect the selective use of mobile devices (Eden et al., 2013)

The desire to be immobile has been discussed in other contexts (see for example, Lemos, 2010). In tourism, research within the backpacking community suggests digital disconnection can also be used selectively as a means to maintain privacy in certain contexts (Germann Molz \& Paris, 2013). Interpersonal influences were evident at the campsite in relation to acceptable use of mobile devices in the context of couples and families. For example, parents wanted to set standards for children and sought to engage them in more corporeal sociability at the campsite. This reflects Garst et al.'s (2009) earlier findings in the USA where parents sought a technology free environment for children. This did not appear to lead to forced disconnection and some participants reflected on acceptable norms of mobile use in larger groups. For example Adam describes:

"I think if I was here as part of a group, doing a group activity, then I might have it switched on because you're not... it's not so much down time as activity time, so you might be more inclined to have your phone on, also to keep in contact with other members of the group, but given it's just the family away, that's different."

There were also issues of maintaining connectivity with home. For example, Donald describes the need to be contactable as "we've got kids, and two of them are still at home, so we've got to be sort of contactable". Person-to-person connectivity has led to a social norm that we can now be contacted at any place and time. This reflects other social expectations placed on tourists by technology (Eden et al., 2013; Pearce \& Gretzel, 2012) and anxieties about disconnection (Gretzel, 2010). 


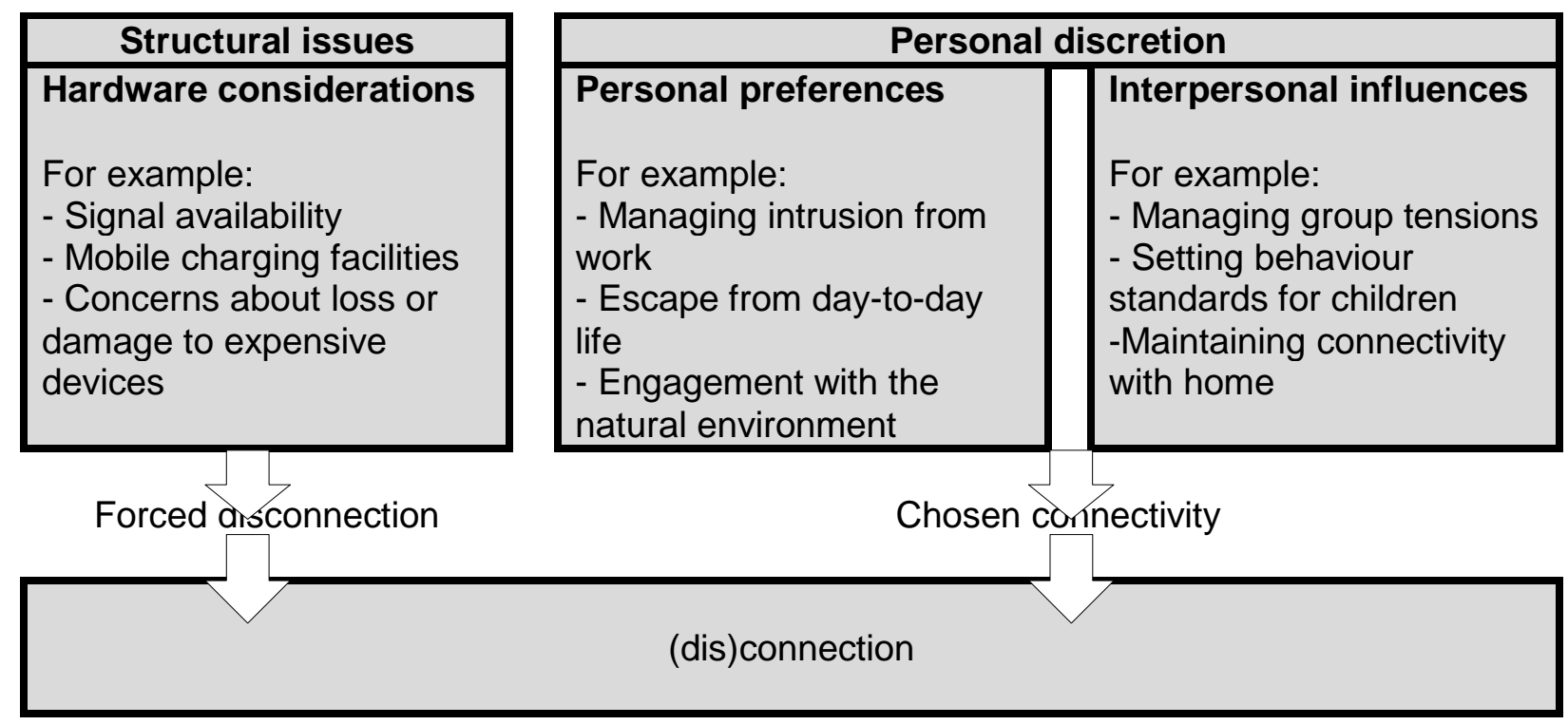

Figure 1. The (dis)connection experience in tourism

Other participants valued being connected with informational, logistical and relational purposes (Campbell \& Kwak, 2011) being most prominent. For instance, Janet describes how her phone was "invaluable" because she "looked up certain things" which she did not have time to research prior to the trip and Ruth describes herself as "very social, I like writing what I have been doing and showing my pictures". Mobile entertainment was rarely mentioned in interviews, which were all with adults; however observations at the campsite suggested some children used mobile devices for this purpose and this gave parents an opportunity to relax. Adults were also observed in personal moments of absorption with devices (Wilken, 2010), providing an opportunity for diversion (Neuhofer, 2016; Oulasvirta, Rattenbury, Ma \& Raita, 2011) from the campsite context.

\subsection{Measuring desire for digital (dis)connection and digital engagement}

Due to the project's focus on mobile technology, the desire for digital disconnection was explored further as a potential barrier to engagement. Given the lack of previous quantitative work in this field at the time, a series of statements were developed based on the qualitative analysis to capture this concept as a latent variable using an agreement scale in the pilot study (Table 1).

Following the pilot two statements were dropped: 'I switch off my phone to avoid intrusion from friends and family' was skewed; and exploratory factor analysis identified that 'I only switch on my mobile to check for messages from close friends and family' loaded highly onto the digital disconnect factor and a second factor related to hardware connectivity. The remaining six items were included in the final survey as a measure of desire for digital disconnection in tourism. 
Table 1. Pilot study 'desire for digital disconnection' statements

\section{Pilot questionnaire statements \\ Camping is a time to avoid mobile communication \\ When camping I like to engage with the natural world and switch off mobile phones}

a switch off my phone to avoid intrusion from friends and family

I switch off my phone to avoid intrusion from work

Mobile technology is an intrusion in a camping holiday

I prefer not to use electronic gadgets when camping

I only carry my mobile phone for emergencies when on holiday

a only switch on my mobile to check for messages from close friends and family

\section{Examples from qualitative data}

"we enjoy this kind of holiday because we switch off"

"we really enjoy walking, being in the countryside, like not texting"

"I leave the phone switched off so people cannot ring me"

"I got a text from somebody at work yesterday, I could do without it really"

"I don't really like that constancy of being contacted all the time."

"I'm just so glad basically to get away from everything and get on holiday. Get away from computers in general."

"I've got an 83 year old mother that I look after, so I don't ever really switch it off because sometimes she calls"

"to contact other people to see what they are doing"

${ }^{a}$ statements dropped following pilot

The final questionnaire contained two questions which gave an indication of digital engagement: type of mobile owned; and use of social network sites. Type of mobile owned indicates the capabilities respondents have to digitally interact during the tourism experience. Three categories were included: smartphones; advanced mobiles, which include internet access and are close to being smartphones, but do not include all the capabilities (Microsoft, 2015); talk and text mobiles. Social media use is widely reported as a significant feature of the tourism experience (see for example, Cohen \& Cohen, 2012; Fotis et al., 2011; Hannam et al., 2014). These two items provide an indicator of the respondent's experience with technology which is important when considering use in tourism contexts (Kang \& Gretzel, 2012). Smartphone ownership (Table 2) reflected UK trends at the time (60\% owned smartphones in July 2012 rising to 68\% by June 2013 (Mintel, 2015b)), however, social media users were under represented (74\% accessed social media as of June 2013 in the UK (Mintel, 2013)). There was a small association of smartphone ownership with relative affluence $\left(x^{2}(8)=19.65, p=.012\right.$, Cramer's $\left.V=.19\right)$.

\subsection{The dilemma of digital connection}

Descriptive analysis of the final sample shows a mixed view of mobile technology avoidance while camping (Table 3) with a relatively even distribution of responses from agreement to disagreement across all statements. This reflects the dilemmas identified in the qualitative analysis. 
Table 2. Digital engagement

\begin{tabular}{lr}
\hline Type of mobile phone & $\%$ \\
\hline No mobile & 2 \\
Smartphone & 60 \\
Advanced mobile (includes internet access) & 17 \\
Talk and text mobile & 20 \\
Not sure & 1 \\
& \\
\hline Use of social network sites & 60 \\
Yes & 40 \\
\hline
\end{tabular}

Table 3. Digital (dis)connection when camping

\begin{tabular}{|c|c|c|c|c|c|c|c|c|c|}
\hline $\begin{array}{l}\text { Statements listed according to } \\
\text { decline in agreement (based } \\
\text { on combined strongly agree } \\
\text { and agree score) }\end{array}$ & 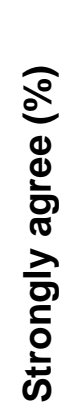 & 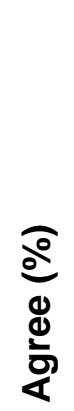 & 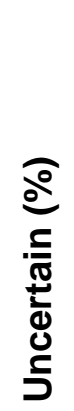 & 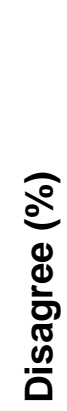 & 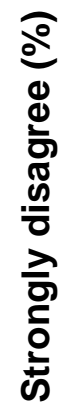 & $M^{a}$ & $S D$ & $S$ & $K$ \\
\hline $\begin{array}{l}\text { Camping is a time to avoid } \\
\text { mobile communication }\end{array}$ & 17 & 33 & 8 & 33 & 9 & 2.83 & 1.30 & .092 & -1.332 \\
\hline $\begin{array}{l}\text { I switch off my phone to avoid } \\
\text { intrusion from work }\end{array}$ & 20 & 26 & 9 & 34 & 12 & 2.92 & 1.36 & -.049 & -1.324 \\
\hline $\begin{array}{l}\text { When camping I like to engage } \\
\text { with the natural world and switch } \\
\text { off mobile phones }\end{array}$ & 16 & 27 & 10 & 34 & 12 & 2.96 & 1.32 & -.041 & -1.388 \\
\hline $\begin{array}{l}\text { I only carry my mobile phone for } \\
\text { emergencies when on holiday }\end{array}$ & 21 & 22 & 6 & 35 & 16 & 3.05 & 1.43 & -.418 & -.944 \\
\hline $\begin{array}{l}\text { I prefer not to use the electronic } \\
\text { gadgets when camping }\end{array}$ & 12 & 25 & 9 & 40 & 14 & 3.19 & 1.29 & -.311 & -1.195 \\
\hline $\begin{array}{l}\text { Mobile technology is an intrusion } \\
\text { in a camping holiday }\end{array}$ & 13 & 18 & 17 & 40 & 12 & 3.21 & 1.23 & -.171 & -1.439 \\
\hline
\end{tabular}

${ }^{a}$ Note: Strongly agree $=1$ to strongly disagree $=5$

A large proportion of respondents (50\%) consider camping a time to avoid mobile communication. Avoidance of work received the second highest level of agreement and aligned with the qualitative data demonstrating work intrusion was a problem for some, but far from all respondents. This relates to the push motive in tourism of seeking to escape (see for example, Krippendorf, 1987; Pearce, 1993). In seeking an explanation for the variability here, it was hypothesised that this would relate to the degree to which mobile phones are used for work purposes, however, this was not measured in the study and needs to be tested in further work. Education level and income were measured which relate indirectly to job status, however, Kruskal Wallis tests indicate no effects. Interview analysis found that some participants had a second work mobile and some had to carry this during tourism. This indicates that work structures, together with mobile technology, have allowed work to intrude into tourism and evidence of this has been found elsewhere (Wang et al., 2014). Conversely, 
some people value the capacity to remain more connected to work (Wang et al., 2014), though there was little evidence of this in the qualitative data.

Engagement with the natural environment received the third highest level of agreement which aligns with tourism pull motives (see for example, Dann, 1981; Crompton, 1979; Krippendorf, 1987; Mannell \& Iso-Ahola, 1987) and Pearce and Gretzel's (2012) finding in dead zones where tourists felt more able to engage in the moment. 'I only carry my mobile phone for emergencies when on holiday' had the highest overall strongly agree score and overall $43 \%$ agreeing. This reflects a social norm to remain connected and a need to manage periods of disconnection (Pearce \& Gretzel, 2012). Since some only carry mobiles for this purpose it raises questions about the value of mobile solutions for other tourism functions in the rural camping tourism context.

\subsection{Demographic factors and digital engagement}

Principal axis factoring was used to generate factor scores for further analysis. Principal axis factoring was employed since the study was exploratory and the results are not generalised beyond the sample (Field, 2013). Given the sample size, the scree plot was examined (Field, 2013) which indicated a one factor solution as anticipated from the pilot study design. Factor scores were generated using the regression method (Table 4). There were no low values in the communalities table, the Kaiser-Meyer-Olkin Measure of Sampling Adequacy was good at 0.900 and Bartlett's Test of Sphericity was significant $(p<0.001)$. The one factor accounted for $72 \%$ of the total variance which is adequate (Doise, Clemence \& LorenziCioldi, 1993).

Table 4. Factor matrix

\begin{tabular}{lr}
\hline When camping I like to engage with the natural world and & $\begin{array}{r}\text { Factor 1 } \\
\text { Digital } \\
\text { disconnect }\end{array}$ \\
switch off mobile phones & .878 \\
Camping is a time to avoid mobile communication & .865 \\
Mobile technology is an intrusion in a camping holiday & .857 \\
I prefer not to use the electronic gadgets when camping & .784 \\
I only carry my mobile phone for emergencies when on & .764 \\
holiday & .719 \\
I switch off my phone to avoid intrusion from work & \\
\hline
\end{tabular}

The factor score was analysed in relation to demographic variables, presence of children in the camping party, type of mobile owned and use of social media. A t-test revealed a significant though small gender effect $(t(281)=2.697, p=.007, r=0.16$, women $(M=-.117$, $S E=.076)$ and Men $(M=.189, S E=.084))$ indicating more desire to digitally disconnect among women. There were no other effects related to demographics or presence of children.

There was a significant difference between social media users and non-users $(t(297)=$ 2.209, $p=.028, r=0.13$, users $(M=.117, S E=.069)$ and non-users $(M=-.135, S E=.091)$, however, the effect size was small. Here the purpose of use of mobile technology would appear to play a role as those who use social networks were less keen to disconnect. The 
use value of mobile devices therefore has some influence on whether mobile technology intrudes during camping tourism. Social networking is viewed as a leisure activity and is often aligned with tourism (Germann Molz, 2012), however, the surveillance associated with social media is not always positive (Hannam et al., 2014) and offers some explanation for the small effect.

Digital disconnect was also explored in relation to type of mobile owned as Kim et al. (2013) suggest smartphone users engage in digital activities that further increase device use. ANOVA revealed a significant but small effect of mobile phone ownership on digital disconnect $(F(2,288)=3.44, p=.034, r=.15)$. Planned comparisons showed a significant linear trend $(F(1,288)=6.66, p=.01)$. Owning a smartphone or advanced mobile significantly increases the desire for digital connection $(t(288)=1.98, p=.049)$ with talk and text mobile owners having greater desire for digital disconnect, however, the effect size was minute $(r=.01)$. However, owning a smartphone did not significantly increase desire for digital connection compared to advance mobile ownership $(t(288)=1.03, p=.305)$.

Therefore, as Kim et al. (2013) suggest, the utility of a more advanced device can influence an individual's likelihood to be engaged with mobiles. In this respect, patterns of digital connection in rural campsite tourism are likely to reflect digital engagement more broadly. However, though significant effects were found for type of mobile owned and use of social media, the effect sizes were small and this pattern is not as marked as anticipated.

There were no age effects related to digital connection, however, age was associated with type of mobile owned $\left(X^{2}(8), p<.001\right)$. The association was medium (Cramer's $\left.V=.33\right)$ and smartphone ownership declined with age. While this reflects patterns in 2013 (Mintel, 2013), this finding will date rapidly as smartphone ownership achieves greater saturation across the population. Given this association a two-way ANOVA examined the effect of age and type of mobile on digital connection. There was no age effect or interaction of age with type of mobile, the effect was all related to the type of mobile.

\subsection{Impact of digital disconnect on desire to use a mobile technology solution}

Given the volume of work focused on enhancing the use of mobile technology in tourism it was important to examine whether desire for digital disconnection reduces the desire to use a mobile technology solution in the tourism setting. Within the wider project a mobile technology solution, in the form of a smartphone app, was developed for campsite tourists. This was designed to facilitate collaborative travel, shopping, information sharing and other activities (Dickinson et al., 2015). The questionnaire asked respondents to indicate their willingness to use the app in two scenarios, lift share and shopping. Spearman's correlations using a one-tailed strategy, on the assumption there would be a directional effect, indicate small effects of digital disconnection for both (lift share: $r_{s}=-.18,95 \% \mathrm{BCa} \mathrm{Cl}[-.293,-.054]$, $p=.001$; shopping: $\left.r_{s}=-.12,95 \% \mathrm{BCa} \mathrm{Cl}[-.233,-.007], p=.016\right)$. The stronger the desire for digital disconnect, the less willing respondents were to use the app. However, while there is an effect and the desire to avoid mobile technology in tourism does to some extent suppress use of a technological solution, the impact of this should not be over stated. As Buhalis and Law (2008, p620) noted back in 2008, tourists are "sophisticated and experienced and therefore are much more difficult to please". This sophistication extends to their mobile technology use which is personal and can be highly selective. Though in general early adopters of technology and innovators are more likely to use new digital products in tourism (Kang \& Gretzel, 2012; Tussyadiah, 2016), developers should not assume this during the tourism experience phase. The study shows fairly high level of desire to disconnect and mobile use is likely to be highly contextual. 


\section{Conclusion}

Mobile technology is a tool with considerable potential in tourism given the mobile nature of the tourist and the needs of tourists related to travel, information seeking on the move, maintaining relationships with friends/family at home and entertainment. This potential must, however, be seen in the light of the desire for digital disconnection. To date there have been reports of a desire to disconnect in tourism linked to ideas such as digital detox and digital addiction, however, there is limited evidence that specifically supports whether digital disconnection takes place. By specifically measuring digital disconnection this paper provides evidence of the extent of the phenomena within the UK camping tourism context and shows up to $50 \%$ of tourists have some desire to disconnect. While the findings are specific to this context, they will have resonance in rural tourism more widely in the UK and elsewhere in Europe.

The study indicates considerable variability in the desire to disconnect with some seeking this while others are very attached to mobile devices that have become integral to their lives. There is also evidence of ambiguity and dilemmas with regard to mobile use in tourism related to a desire to 'get away from it all' while realising the value of connectivity to perform useful tourism functions. The variability in digital disconnection was not explained by demographic factors, although there was a small gender effect. Digital engagement had a similarly small effect on disconnection, with smartphone owners and social media users more inclined to digital connection reflecting patterns found in other domains (Kim et al., 2013). This indicates that though some tourists seek to go 'off grid', this is not whole heartedly embraced and not as strongly related to digital engagement in general as might be expected.

The growing use of mobile technology solutions in tourism assume that tourists will be digitally connected. This study raises questions about this assumption, at least during the tourism consumption experience phase, particularly as quite a high proportion of respondents sought some degree of disconnection regardless of their capacity to connect and digital engagement in general. The study also found a small, but significant effect of digital disconnection on desire to use a tourism related smartphone app. A clear message is that some tourists will seek to disengage from mobile technology and will consider it an intrusion where its use is required. The decision to disconnect is likely to be highly personal and contextual to individual experiences and circumstances. Over time this picture will evolve. At the time of the survey in 2013 , smartphones were relatively new (ownership was around $68 \%$ of the population). This reflects a period of rapid adoption of new technology and a social transition during which mobile devices became increasingly pervasive in a range of contexts. In the interim time period, there have been media stories reporting a need for digital detox, some of which have specifically contextualised this to tourism. The findings reported in this paper therefore represent a snapshot and it is unclear whether the connection-disconnection dilemma will remain, grow in prominence or decrease as new technological norms emerge. However, an important message is that the tourist is not "always connected".

A separate but related issue is whether 'escape', as a push motive in tourism, remains or whether this has evolved given that mobile technology can instantly transport us back to home and work environments. Research has shown how digital connection alters the experience of travelling (Gretzel, 2010; Paris et al., 2015). Further study therefore needs to explore whether the concept of 'escape' has evolved, whether we ever really sought escape from our day-to-day lives and how the mobile device might be enabling escape in other forms.

Finally, while the questions on digital disconnection were purposefully developed for this study and focus on the campsite tourism context, they could be adapted to other contexts to 
measure digital (dis)connection. This could usefully inform destination policy decisions on development of technological solutions or decisions to limit mobile device use in tourism contexts such as natural areas or museums. Further research is needed in other tourism context such as city tourism and mass resort tourism to explore the extent to which desire for digital disconnection pervades other settings.

\section{Acknowledgements}

This work was partially funded by the Research Councils UK as part of the Sixth Sense Transport (6ST) project (EP/J004650/1).

\section{References}

Brooks, S., \& Longstreet, P. (2015). Social networking's peril: Cognitive absorption, social networking usage, and depression. Cyberpsychology: Journal of Psychosocial Research on Cyberspace, 9(4), 21-44.

Bryman, A. (2001). Social Research Methods. Oxford: Oxford University Press.

Buhalis, D., \& Law, R. (2008). Progress in information technology and tourism management: 20 years on and 10 years after the internet - The state of eTourism research. Tourism Management, 29, 609-623.

Campbell, S.W., \& Kwak, N. (2011). Mobile Communication and Civil Society: Linking Patterns and Places of Use to Engagement with Others in Public. Human Communication Research, 37, 207-222.

Clawson, M., \& Knetsch, J.L. (1966). Economics of Outdoor Education. Baltimore: The Johns Hopkin University Press.

Cohen, E., \& Cohen, S. (2012). Current sociological theories and issues in tourism. Annals of Tourism Research, 39(4), 2177-2202.

Crompton, J. L. (1979). Motivations for pleasure vacation. Annals of Tourism Research, 6(4), 408-424.

Dann, G. M. (1981). Tourist motivation an appraisal. Annals of Tourism Research, 8(2), 187219.

de Oliveira Nunes, M., \& Mayer, V.F. (2014). Mobile technology, games and nature areas: The tourist perspective. Tourism \& Management Studies, 10(1), 53-58.

Dickinson, J.E., \& Peeters, P. (2012) Time, Tourism Consumption and Sustainable Development. International Journal of Tourism Research, 16(1), 11-21.

Dickinson, J.E., Cherrett, T., Hibbert, J., Winstanley, C., Shingleton, D., Davies, N., Norgate, S., Speed, C. (2015). Fundamental challenges in designing a collaborative travel app. Transport Policy, 44, 28-36.

Dickinson, J.E., Filimonau, V., Cherrett, T., Davies, N., Norgate, S., Speed, C., Winstanley, C. (2013). Understanding temporal rhythms and travel behaviour at destinations: potential ways to achieve more sustainable travel. Journal of Sustainable Tourism, 21(7), 1070-1090.

Dickinson, J.E., Filimonau, V., Hibbert, F., Cherrett, T., Davies, N., Norgate, S., Speed, C., Winstanley, C. (2016). Tourism communities and social ties: the role of online and offline tourist social networks in building social capital and sustainable practice. Journal of Sustainable Tourism, DOI 10.1080/09669582.2016.1182538.

Dickinson, J.E., Ghali, K., Cherrett, T., Speed, C., Davies, N., Norgate, S. (2014). Tourism and the smartphone app: capabilities, emerging practice and scope in the travel domain. Current Issues in Tourism, 17(1), 84-101.

Doise, W., Clemence, A. \& Lorenzi-Cioldi, F. (1993). The Quantitative Analysis of Social Representations. London: Harvester Wheatshead.

Eden, H., Gretzel, U., \& Mistilis, N. (2013). Negotiating technology use to make vacations special. e-Review of Tourism Research (eRTR). Available at: 
http://agrilife.org/ertr/files/2013/03/enter2013_submission_50.pdf (accessed 12 May 2016).

European Commission (2015). Commission welcomes agreement to end roaming charges and to guarantee an open Internet. On-line document available at: http://europa.eu/rapid/press-release IP-15-5265 en.htm (accessed 12th February 2016).

EuroStat (2012). Tourism statistics at regional level. On-line document available at: http://epp.eurostat.ec.europa.eu/statistics explained/index.php/Tourism statistics at regional level\#Camping.

Field, A. (2013). Discovering Statistics Using IBM SPSS Statistics. 4th edition. London: Sage.

Fortunati, L., Taipale, S., \& de Luca, F. (2013). What happened to body-to-body sociability? Social Science Research, 42, 893-905.

Fotis, J., Buhalis, D., \& Rossides, N. (2011). Social Media Impact on Holiday Travel Planning: The Case of the Russian and the FSU Markets. International Journal of Online Marketing, 1(4), 1-19.

Garst, B.A., Williams, D.R., \& Roggenbuck, J.W. (2009). Exploring Early Twenty-First Century Developed Forest Camping Experiences and Meanings. Leisure Sciences, 32(1), 90-107.

Germann Molz, J. (2012). Travel connections: Tourism, technology and togetherness in a mobile world. London: Routledge.

Germann Molz, J., \& Paris, C. (2013). The social affordances of flashpacking: Exploring the mobility nexus of travel and communication. Mobilities, 10(2), 173-192.

Giles, D.C. (2002). Advanced Research Methods in Psychology. Hove: Routledge.

Gretzel, U. (2010). Travel in the Network: Redirected Gazes, Ubiquitous Connections and New Frontiers. In M. Levina \& G. Kien (Eds.), Post-global Network and Everyday Life (pp. 41-58). New York: Peter Lang.

Gretzel, U. (2014). Travel Unplugged: The case of Lord Howe Island, Australia. In K. Mackay (Ed.), Proceedings of the TTRA Canada Annual Conference. Yellowknife, Canada, September 24-26.

Guba, E.G., \& Lincoln, Y.S. (1998). Competing Paradigms in Qualitative Research. In N.K. Denzin \& Y.S. Lincoln (Eds.), The landscape of qualitative research: Theories and issues (pp. 195-220). London: Sage.

Hall, C.M. (2003). Introduction to tourism: dimensions, and issues. Frenchs Forest, N.S.W.: Hospitality Press.

Hannam, K., Butler, G., \& Paris, C.M. (2014). Developments and key issues in tourism mobilities. Annals of Tourism Research, 44, 171-185.

Hardy, A., Gretzel, U., \& Hanson, D. (2013). Travelling neo-tribes: conceptualising recreational vehicle users. Journal of Tourism and Cultural Change, 11(1-2), 48-60.

Harwood, J., Dooley, J., Scott, A., \& Joiner, R. (2014). Constantly connected: The effects of smartdevices on mental health. Computers in Human Behavior, 34, 267-272.

Hassell, S., Moore, S.A., \& Macbeth, J. (2015). Exploring the Motivations, Experiences and Meanings of Camping in National Parks. Leisure Sciences, 37(3), 269-287.

Hibbert, J.F, Dickinson, J.E., \& Curtin, S. (2013). Understanding the influence of interpersonal relationships on identity and tourism travel. Anatolia: An International Journal of Tourism and Hospitality Research, 24(1), 30-39.

Humphreys, L. (2010). Mobile social networks and urban public space. New Media and Society, 12(5), 763-778.

Jafari, J. (1987) Tourism models: the sociocultural aspects. Tourism Management, 8(2), 151159.

Kang, M., \& Gretzel, U. (2012). Perceptions of museum podcast tours: Effects of consumer innovativeness, Internet familiarity and podcasting affinity on performance expectancies. Tourism Management Perspectives, 4, 155-163. 
Kim, Y.H., Kim, D.J., \& Wachter, K. (2013). A study of mobile user engagement (MoEN): engagement motivations, perceived value, satisfaction, and continued engagement intention. Decision Support Systems, 56(2013), 361-370.

Klein, O. (2004). Social Perception of Time, Distance and High-Speed Transportation. Time \& Society, 13(2/3), 245-263.

Krippendorf, J. (1987). The holiday makers: understanding the impact of leisure and travel. London: Heinemann.

Lalicic, L., \& Weismayer, C. (2016). Being passionate about the mobile while travelling. Current Issues in Tourism, doi.org/10.1080/13683500.2016.1141179.

Lay, K. (2014). "If hell is mobiles and e-mail, visit Scotland, tourism bosses urge." Times [London, England] 17 Mar. 2014, 16.

Lemos, A. (2010). Post-Mass Media Functions, Locative Media, and Informational Territories: New Ways of Thinking About Territory, Place, and Mobility in Contemporary Society. Space and Culture, 13(4), 403-420.

Llamas, R., \& Belk, R.W. (2013). Living in a digital world. The Routledge Companion to Digital Consumption. Abingdon: Routledge.

MacKay, K., \& Vogt, C. (2012). Information technology in everyday and vacation contexts. Annals of Tourism Research, 39(3), 1380-1401.

Mannell, R. C., \& Iso-Ahola, S. E. (1987). Psychological nature of leisure and tourism experience. Annals of Tourism Research, 14(3), 314-331.

Microsoft (2015). Mobile phones, feature phones and smartphones: the differences. Available at: https://blogs.windows.com/devices/2012/07/24/mobile-phones-featurephones-and-smartphones-the-differences/ (accessed 20 May 2016).

Mikkelsen, M.V., \& Cohen, S.A. (2015). Freedom in mundane mobilities: Caravanning in Denmark. Tourism Geographies, 17(5), 663-681.

Mintel (2013). Digital Trends Winter - UK - December 2013. London: Mintel Group Ltd.

Mintel (2015a). Digital Trends Winter - UK - December 2015. London: Mintel Group Ltd.

Mintel (2015b). Digital Trends Spring - UK - March 2015. London: Mintel Group Ltd.

Mintel (2016). Camping and caravanning UK - April 2016. London: Mintel Group Ltd.

Moscado, G. (2009). Tourism and quality of life: Towards a more critical approach. Tourism and Hospitality Research, 9, 159-170.

Munar, A. M., \& Jacobsen, J.K.S. (2014). Motivations for sharing tourism experiences through social media. Tourism Management, 43, 46-54.

Neuhofer, B. (2016). Value Co-creation and Co-destruction in Connected Tourist Experiences. In I. Tussyadiah \& A. Inversini (Eds.), Information and Communication Technologies in Tourism 2016 (pp. 779-792). New York: Springer.

Neuhofer, B., Buhalis, D., \& Ladkin, A. (2014) A Typology of Technology-Enhanced Tourism Experiences. International Journal of Tourism Research, 16, 340-350.

Oulasvirta, A., Rattenbury, T., Ma, L., \& Raita, E. (2011). Habits make smartphone use more pervasive. Personal and Ubiquitous Computing, 16(1), 1-10.

Paris, C.M., Berger, E.A., Rubin, S., \& Casson, M. (2015). Disconnected and Unplugged: Experiences of Technology Induced Anxieties and Tensions While Traveling. In I. Tussyadiah, A. Inversini (Eds.), Information and Communication Technologies in Tourism (pp. 803-816). London: Springer.

Patterson, M.E., Watson, A.E., Leopold, A., Williams, D.R., \& Roggenbuck, J.R. (1998) An Hermeneutic Approach to Studying the Nature of Wilderness Experiences. Journal of Leisure Research, 30(4), 423-452.

Pearce, P. (1993). Fundamentals of Tourist Motivation. In D. Pearce and R. Butler (Eds.), Tourism Research: Critiques and Challenges (pp. 85-105). London: Routledge and Kegan Paul.

Pearce, P., \& Gretzel, U. (2012). Tourism in technology dead zones: Documenting experiential dimensions. International Journal of Tourism Sciences, 12(2), 1-20.

Pearce, P. L. (2011). Tourist behaviour and the contemporary world. Bristol: Channel View Publications. 
Purbeck Heritage Committee (2002). Making Purbeck More Special: A strategy for the Purbeck Heritage Area 2002-7. Wareham: Purbeck Heritage Committee.

Samaha, M., \& Hawi, N.S. (2016). Relationships among smartphone addiction, stress, academic performance, and satisfaction with life. Computers in Human Behavior, 57, 321-325.

Sheller, M. (2004). Mobile publics: beyond the network perspective. Environment and Planning D: Society and Space, 22, 39-52.

Smith, M., \& Puczkó, L. (2015). More than a special interest: defining and determining the demand for health tourism. Tourism Recreation Research, 40:2, 205-219.

Turel, O., Serenko, A., \& Bontis, N. (2011). Family and work-related consequences of addiction to organizational pervasive technologies. Information and Management, 48, 88-95.

Turner, V. (1977). Variations on a Theme of Liminahty. In S. Moore. and E. Myerhoff (Eds.), Secular Rituals (pp. 27-41). Amsterdam: Van Gorcum.

Tussyadiah, P. (2016). The Influence of Innovativeness on On-Site Smartphone Use among American Travelers: Implications for Context-based Push Marketing. Journal of Travel \& Tourism Marketing, DOI: 10.1080/10548408.2015.1068263

Uysal, M., Sirgy, M.J., Woo, E., \& Kim, H. (2016). Quality of life (QOL) and well-being research in tourism. Tourism Management, 53, 244-261.

Vespestad, M.K., \& Lindberg F. (2011). Understanding nature-based tourist experiences: an ontological analysis. Current Issues in Tourism, 14(6), 563-580.

Wajcman, J. (2008). Life in the fast lane? Towards a sociology of technology and time. The British Journal of Sociology, 59(1) 59-77.

Wang, D., Xiang, Z., \& Fesenmaier, D.R. (2016) Smartphone Use in Everyday Life and Travel. Journal of Travel Research, DOI: 10.1177/0047287514535847.

Wang, D., Xiang, Z., \& Fesenmaier, D.R. (2014) Adapting to the mobile world: A model of smartphone use. Annals of Tourism Research, 48, 11-26.

Wilken, R. (2010). A community of strangers? Mobile media, art, tactility and urban encounters with the other. Mobilities, 5(4), 449-468.

Wittel, A. (2001). Toward a Network Sociality. Theory, Culture \& Society, 18(6), 51-76. 